\title{
Analysis of Complex HSLA Steel Microstructures by Various Techniques
}

\author{
M. J. Merwin, C. T. Becker, and D. R. Giansante
}

United States Steel Corporation, 800 East Waterfront Drive, Munhall, PA 15120

The present study was undertaken to better understand the relationship between complex ferritic microstructures observed by conventional means and electron backscattered diffraction (EBSD). An HSLA steel, of nominal composition $0.05 \mathrm{C}-1.6 \mathrm{Mn}-0.25 \mathrm{Mo}-0.08 \mathrm{Nb}$, was cooled with varied cooling rates to achieve a range of microstructures. Hot-rolled samples were reheated to $900^{\circ} \mathrm{C}$ and continuously cooled at various rates, defined by the cooling time between $800^{\circ} \mathrm{C}$ and $500^{\circ} \mathrm{C}$ $\left(\Delta \mathrm{t}_{8-5}\right)$, which ranged from 3 seconds to 300 seconds. Light microscopy was performed after etching with $2 \%$ Nital, $4 \%$ Picral, and LePera's reagent. Image analysis was conducted on etched specimens to determine grain size and martensite content. EBSD analysis was conducted on a LEO Supra 25 scanning electron microscope, equipped with an EDAX-TSL Hikari EBSD system, over a $100 \mu \mathrm{m} \times 100 \mu \mathrm{m}$ area with a $100 \mathrm{~nm}$ step size. EBSD scans were cleaned by grain dilation using a 2 degree grain threshold angle (GTA) and a 5 pixel minimum grain size.

Example photomicrographs and EBSD Image Quality (IQ) maps are shown in Figure 1. This analysis focused on the ferrite phase as EBSD revealed that the samples in this study to have at most 0.2 percent austenite. Figure 2 presents the grain size as determined by light microscopy and EBSD with $2^{\circ}$ and $15^{\circ}$ GTA. Area compensated average grain size was determined by the method in OIM Analysis [1]. The different measurement methods deliver a similar correlation between grain size and $\Delta \mathrm{t}_{8-5}$, but there are differences in the detail. Light microscopy generally yields larger grain sizes, likely do to incomplete boundary etching and issues in thresholding. The $15^{\circ} \mathrm{GTA}$ reported larger grains than did the $2^{\circ} \mathrm{GTA}$, particularly when considering the area-compensated grain size for fast cooling rate specimens. Also shown in Figure 2 is the martensite content as measured in light microscopy (LePera's reagent) and EBSD. The EBSD estimation was conducted based on the grey levels in IQ maps following the principles presented by Wilson, et al [2]. The overall content of martensite observed was similar for light microscopy and EBSD. However, the light microscopy measurements were found to fluctuate more than the EBSD measurements.

Example IQ distributions are shown in Figure 3. In this work the grain average IQ has been considered. Using a $15^{\circ} \mathrm{GTA}$, low-angle boundaries found in bainite and martensite islands will tend to reduce the IQ of the grain, potentially allowing differentiation between the various ferrite forms. The grain average IQ method appears to emphasize the ferrite and martensite grains (high and low IQ peaks) for the slower cooling rates, and the faster cooling rate shows predominantly intermediate IQ indicative of bainite. The small martensite islands present in the $\Delta \mathrm{t}_{8-5}=3 \mathrm{~s}$ do not appear to be easily quantified by the grain average IQ distribution. Also of note, the $\Delta \mathrm{t}_{8-5}=3 \mathrm{~s}$ sample alone demonstrated a strong peak in misorientation angle near $45^{\circ}$, which as been associated with granular bainite by Zajac, et al [3].

\section{References}

1. OIM Analysis, Version 5.2, EDAX-TSL.

2. A. W. Wilson, et al., Scripta Materialia, vol. 45 (2001), pp. 1335-1340.

3. S. Zajac, et al., Materials Science Forum, vols. 500-501 (2005), pp. 387-394. 


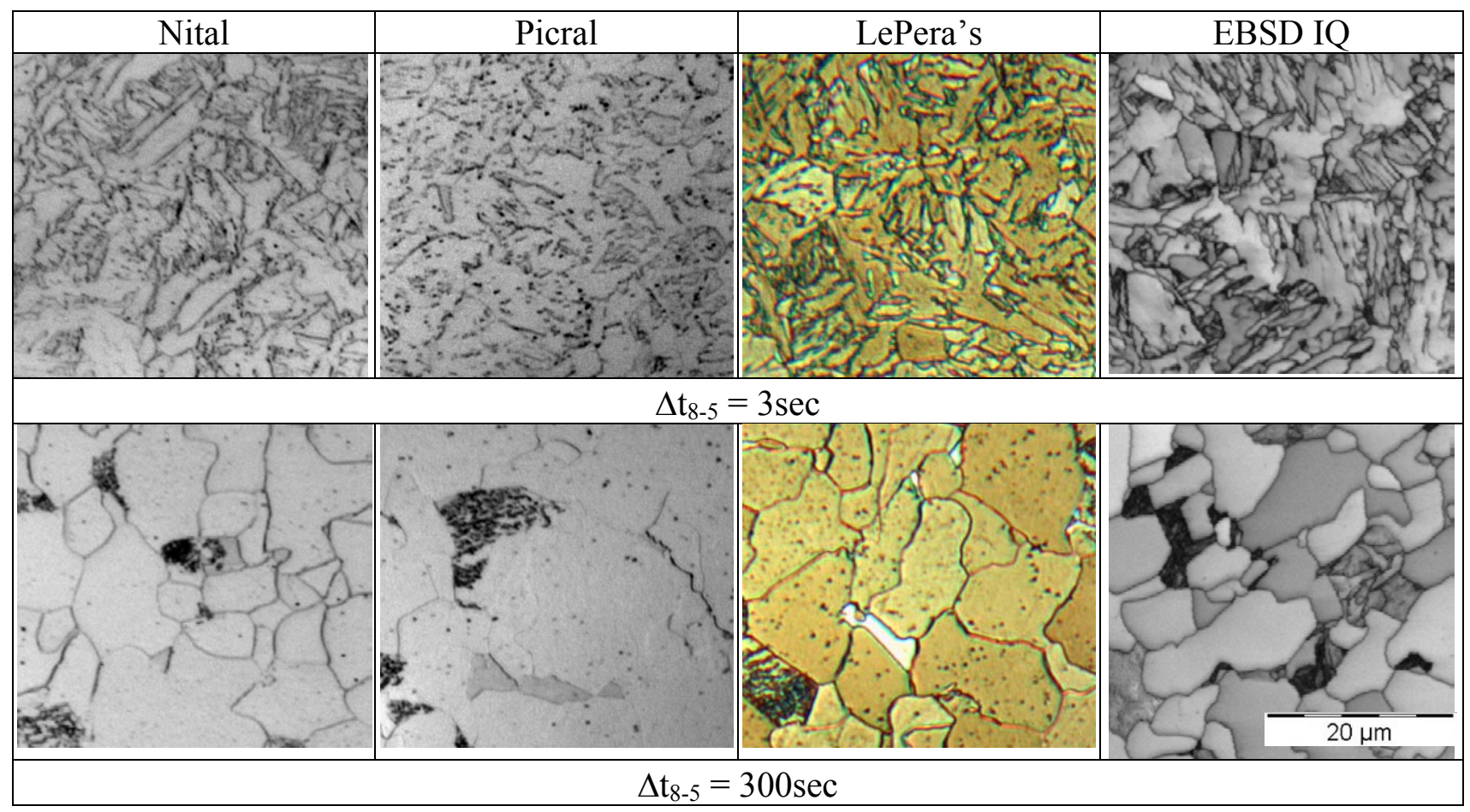

Figure 1. Photomicrographs and Image Quality maps from high and low cooling rate specimens.
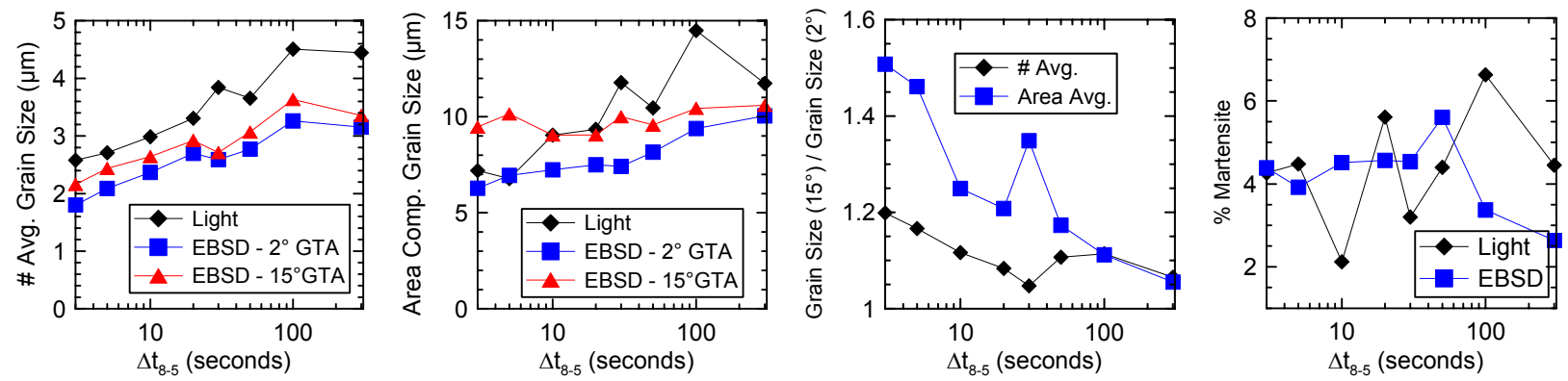

Figure 2. Grain size and martensite content as a function of $\Delta \mathrm{t}_{8-5}$.
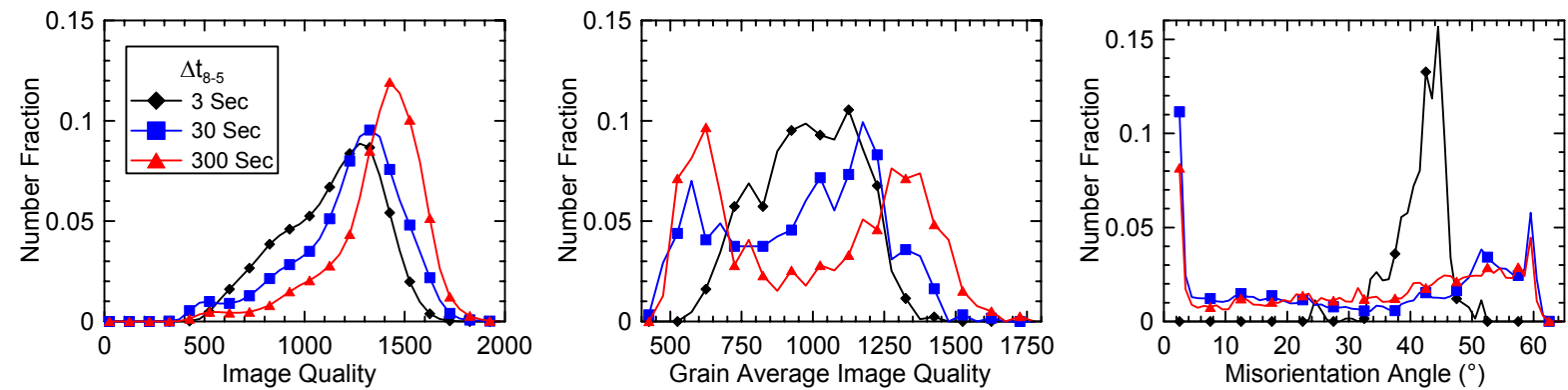

Figure 3. Distributions for ferrite pixel IQ, ferrite grain average IQ, and misorientation angle.

The material in this paper is intended for general information only. Any use of this material in relation to any specific application should be based on independent examination and verification of its unrestricted availability for such use, and determination of suitability for the application by professionally qualified personnel. No license under any United States Steel Corporation patents or other proprietary interest is implied by the publication of this paper. Those making use of or relying upon the material assume all risks and liability arising from such use or reliance. 